\section{Commentary: It's better to be alone than in bad company...at least for bioprosthesis}

\author{
Victor Dayan, MD, PhD
}

Differential benefits and risks with the use of bioprostheses and mechanical aortic valves are an issue of debate, and any large registry data that address these issues are always novel and welcome. Rodriguez-Caulo and colleagues ${ }^{1}$ evaluated survival and major adverse cardiac events as primary outcomes in a large registry that included 50- to 65-year-old patients who underwent isolated aortic valve replacement (AVR) from 2000 to 2018 at 27 hospitals in Spain. Propensity matching (2:1) yielded 1822 patients with a mechanical prosthesis and 911 patients with a bioprosthesis. After a median of 6-8 years, survival was similar between both groups. Patients with a mechanical prosthesis had a higher risk for bleeding, and patients with a bioprosthesis had a higher risk for reintervention. ${ }^{1}$

When evaluating long-term survival in patients with a bioprosthesis versus mechanical prosthesis through retrospective studies, it is critical to distinguish if included patients underwent isolated AVR or not. Patients aged 50-65 years who require coronary artery bypass grafting (CABG) might receive a mechanical prosthesis to avoid reintervention with patent grafts. This portrays a strong selection bias difficult to adjust by propensity match. Kytö and colleagues ${ }^{2}$ recently showed that 10 -year allcause mortality was higher in patients with a bioprosthesis in a retrospective study. Although the 10-year mortality in those with a mechanical valve in the study by Kytö and colleagues $^{2}(18.6 \%)$ was similar to that in the study by Rodriguez-Caulo and colleagues ${ }^{1}(17 \%)$, this was not the case for the bioprosthesis $(27.6 \%$ and $19 \%$,

From the Centro Cardiovascular Universitario, Universidad de la Republica, Montevideo, Uruguay.

Disclosures: The author reported no conflicts of interest.

The Journal policy requires editors and reviewers to disclose conflicts of interest and to decline handling or reviewing manuscripts for which they may have a conflict of interest. The editors and reviewers of this article have no conflicts of interest.

Received for publication Feb 6, 2021; revisions received Feb 6, 2021; accepted for publication Feb 8, 2021; available ahead of print Feb 19, 2021.

Address for reprints: Victor Dayan, MD, PhD, Centro Cardiovascular Universitario, Universidad de la Republica, 26 de Marzo 3459/602, Montevideo, Uruguay (E-mail: victor_dayan@hotmail.com).

J Thorac Cardiovasc Surg 2023;165:618-9

$0022-5223 / \$ 36.00$

Copyright (c) 2021 by The American Association for Thoracic Surgery

https://doi.org/10.1016/j.jtcvs.2021.02.048

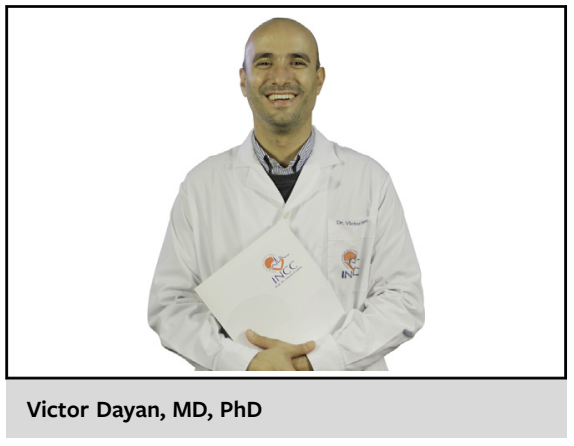

CENTRAL MESSAGE

Bioprosthesis is an excellent option for young patients who undergo isolated AVR. Although reintervention is higher than mechanical, mortality associated with re-do AVR did not affect survival.

respectively). The main difference between the studies by Rodriguez-Caulo and colleagues ${ }^{1}$ and Kytö and colleagues $^{2}$ is the inclusion of concomitant CABG in the latter. Hirji and colleagues ${ }^{3}$ found no difference in survival between bioprosthesis and mechanical groups in a young cohort of patients with a low incidence of CABG. A recent meta-analysis comparing bioprosthesis and mechanical groups (irrespective of isolated or not AVR) found a survival benefit for mechanical. ${ }^{4}$ Bioprostheses are associated with more reintervention, and patients who underwent CABG during the first surgery have a higher operative risk during the reintervention. Therefore, we should be careful when comparing outcomes from studies with isolated AVR and AVR with concomitant CABG; furthermore, meta-analyses studying this association should include meta-regression with concomitant CABG as a moderator before reaching any conclusion.

The authors present an interesting hypothesis centered on the improvement of bioprosthesis quality as an explanation to the lower reintervention rates in patients with bioprostheses during 2 different time periods (20002008 and 2009-2018). Although the improvement in the quality of bioprostheses is undeniable, there are 2 main limitations to this conclusion: (1) Reintervention is a "too late" parameter to be used as an indicator for prosthesis durability; and (2) comparing reintervention in 
patients with a bioprosthesis between 2 groups with different time periods carries an implicit risk of bias. Duration of follow-up and therefore time for prosthesis degeneration requiring reintervention will be longer in the 2000-2008 group.

The main take-home message is that bioprostheses are an excellent option for young patients (aged 50-65 years) who undergo isolated AVR. Although reintervention is higher than in those with mechanical AVR, mortality associated with re-do isolated AVR is not reflected in long-term survival.

\section{References}

1. Rodriguez-Caulo EA, Blanco-Herrera O, Berastegui E, Arias-Dachary J, Souaf S Parody G, et al; SPAVALVE study group. Biological versus mechanical prostheses for aortic valve replacement. J Thorac Cardiovasc Surg. 2023;165:609-17.e7.

2. Kytö V, Sipilä J, Ahtela E, Rautava P, Gunn J. Mechanical versus biologic prostheses for surgical aortic valve replacement in patients aged 50 to 70 . Ann Thorac Surg. 2020;110:102-10.

3. Hirji SA, Kolkailah AA, Ramirez-Del Val F, Lee J, McGurk S, Pelletier M, et al Mechanical versus bioprosthetic aortic valve replacement in patients aged 50 years and younger. Ann Thorac Surg. 2018;106:1113-20.

4. Diaz R, Hernandez-Vaquero D, Alvarez-Cabo R, Avanzas P, Silva J, Moris C, et al Long-term outcomes of mechanical versus biological aortic valve prosthesis: systematic review and meta-analysis. J Thorac Cardiovasc Surg. 2019;158:706-14.e18.

\section{Commentary: Surgical aortic valve replacement for the younger patient, but which one?}

\author{
Norman Briffa, MB, MD, FRCS(CTh)
}

In this multicenter observational study from Spain, ${ }^{1}$ outcomes of 5215 patients age 55 to 65 years who underwent isolated surgical aortic valve replacement (SAVR) were examined. The authors used propensity matching to create 2 groups: patients who received a mechanical prosthesis $(\mathrm{n}=1822)$ and those who received a tissue prosthesis $(\mathrm{n}=911)$.

The main finding from the study was that at 15 years, there was no significant difference in survival or freedom from a composite of valve-related morbidities. This study demonstrates why the question of prosthetic choice in younger patients is still pertinent and does not have a straightforward answer. When commenting on the prosthetic type, it is useful, like all good seekers of the truth, to go back to the original source: 2 randomized trials published at the dawn of this millennium. ${ }^{2,3}$ These studies demonstrated that patients with

\footnotetext{
From the Sheffield Teaching Hospitals NHS Trust, University of Sheffield, Sheffield, United Kingdom.

Disclosures: The author reported no conflicts of interest.

The Journal policy requires editors and reviewers to disclose conflicts of interest and to decline handling or reviewing manuscripts for which they may have a conflict of interest. The editors and reviewers of this article have no conflicts of interest.

Received for publication Feb 8, 2021; revisions received Feb 8, 2021; accepted for publication Feb 9, 2021; available ahead of print Feb 19, 2021.

Address for reprints: Norman Briffa, MB, MD, FRCS(CTh), Cardiothoracic Centre, Chesterman Wing, Northern General Hospital, Herries Rd, Sheffield, United Kingdom S5 7AU (E-mail: N.Briffa@sheffield.ac.uk).

J Thorac Cardiovasc Surg 2023;165:619-20 0022-5223/\$36.00

Crown Copyright $(\subset) 2021$ Published by Elsevier Inc. on behalf of The American Association for Thoracic Surgery

https://doi.org/10.1016/j.jtcvs.2021.02.044
}

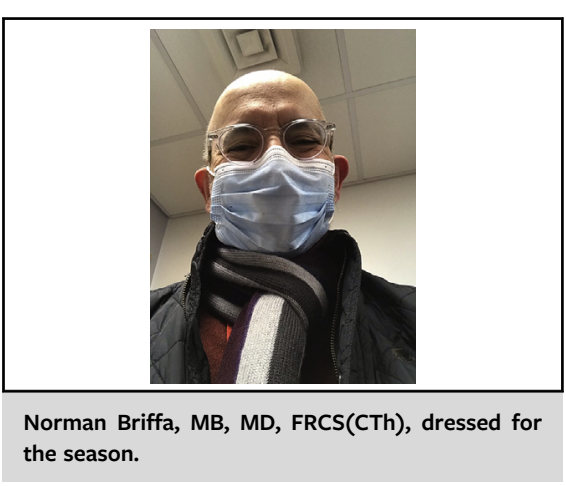

CENTRAL MESSAGE

The treatment of aortic valve disease in patients age $<65$ years remains surgical. Patient choice and attitudes toward complications associated with either prosthesis remain key to the device used.

aortic mechanical prostheses were more likely to survive for 15 years and more likely to suffer anticoagulant-related bleeding. Those with a tissue prosthesis were more likely to require reintervention. The latter 2 findings have been confirmed in retrospective observational studies, ${ }^{4}$ including this one. Unlike in many countries, in Spain the utilization of tissue valves in patients under 70 remains low at under $30 \%$. The main strength of this publication is in the large numbers expected in the study of a national registry.

The study has some methodological weaknesses. Survival, hospital admissions, and diagnoses were established not by validated national registries, but rather by telephone 